\title{
Rheological Model of Concrete Shrinkage
}

\author{
Chatarina Niken ${ }^{1 *}$, Elly Tjahjono ${ }^{2}$, FX Supartono ${ }^{2}$ \\ ${ }^{1}$ Department of Civil Engineering, Faculty of Engineering, Universitas Lampung, Jl. Sumantri Brojonegoro \\ No. 1, Bandar Lampung 35141, Indonesia \\ ${ }^{2}$ Department of Civil Engineering, Faculty of Engineering, Universitas Indonesia, Kampus UI Depok, \\ Depok 16424, Indonesia
}

\begin{abstract}
This paper discusses the shrinkage rheological model of high-performance concrete with a compressive strength of $60 \mathrm{MPa}$. This is based on experimental research in Indonesia. Three specimens measuring $150 \mathrm{~mm} \times 150 \mathrm{~mm} \times 600 \mathrm{~mm}$ were used. Specimens were placed in a conditioned room with a temperature of $283 \mathrm{oC}$ and relative humidity of $72 \pm 5 \%$. Observations were conducted over 7-800 days using an embedded vibrating wire strain gauge for each specimen. As a result, the shrinkage rheological model was single or multi Kelvin-Voigt in series with timedependent disturber flow in it. Disturber flow depends on product hydration growth, weather, pore number, size, and distribution. The model agrees with experimental results. Moreover, it also fits the results using high strength concrete column and high strength self - compacting concrete cylinder.
\end{abstract}

Keywords: Concrete; Model; Rheology; Shrinkage

\section{Introduction}

Shrinking and expansion naturally occur in the process of forming concrete, mainly due to hydration reactions. Shrinking and expanding causes deformation in concrete. Deformation is the most important structural mechanism that influences building performance. This performance is determined by mixture design, casting time and methods, compaction, and treatment immediately following casting, curing, and loading.

Creep and shrinkage modeling of concrete using solidification theory was done (Hedegaard, 2020). A review of the shrinkage behavior of conventional and nonconventional concrete was published (Elzokra et al., 2020). Performance is chiefly characterized by applying a rheological model (Bentz et al., 2018). Rheology applies to mixture design and quality control, segregation, pumping, formwork pressure, and surface finish (Ferraris et al., 2017).

Rheology is a science of deformation and flow. Heraclitus, the Greek philosopher, has revealed: "Everything flows; everything changes," which means something that moves will alter and can change. This statement is the basic idea of rheology (Hackley and Ferraris, 2001). Particle flow occurs in concrete since its mixing. Because the viscosity change in concrete is influenced by the hydration process and environmental humidity, the change in shear stress is not directly proportional to the shear rate, so non-Newtonian behavior 
occurs. Non-Newtonian particle-laden fluids are more complex due to various factors (Mau et al., 2020).

Shrinkage can be defined as a time-dependent decrease in concrete volume (American Concrete Institute, 1992). In fresh conditions, the paste rheological model is useful in designing SCC mixtures and reducing the extent of laboratory work, testing time, and materials used. For hard concrete, a long-term deformation rheological model was mentioned by Sobotka (1962) as H-StV $\left.\left.\right|_{N-H}\right|_{N} \mid S t V=H-B-(K \mid S t V)$ (H: Hooke, StV: St Venant, N: Newton liquid, B: Bingham, K: Kelvin solid). Sobotka (1984) and Ferraris (1999) also stated that the long-term deformation of concrete fits well with the Bingham model (HStV l N). Because the first model as described above is Hooke (H), it means that the increase in load is directly proportional to the rate of strain. This means that the sample is under external load, so what is happening is creep. Until now, concrete rheological models were only for creep. This matter is based on deformation and particle flow caused by the applied load. In fact, without an applied load, there are microscopic flows in the concrete due to microprestresses-solidification. In rheology, there is no clear border between solid and liquid. Based on this condition, shrinkage can be modeled rheologically. By seeing the rheological model, concrete behavior can be understood quickly and easily.

Shrinkage is a natural phenomenon that is also due to moving particles and water. After curing, concrete starts to deform with environmental influences; thus, shrinkage is influenced by external supply water, so the climate plays an important role. Because the hydration process may occur for a long time, shrinkage occurs simultaneously with hydration, causing the shrinkage mechanism to become complex. A full understanding of long-term shrinkage behavior is needed for concrete design with good performance. A full understanding of long-term shrinkage behavior is needed for concrete design to reach good performance.

The objective of this research is to create a shrinkage rheological model to illustrate the deformation behavior of concrete under the influence of hydration and climate.

\section{Methods}

This research was conducted in Jakarta, Indonesia, within humid, tropical weather. This study was performed experimentally using three specimens of $150 \mathrm{~mm} \times 150 \mathrm{~mm} \times 600 \mathrm{~mm}$, according to ASTM C78-08, with one embedded vibrating wire strain gauge (SG) for each specimen. The position of the SG can be seen in Figure 1a (i.e., five $\mathrm{cm}$ from the end of the specimen). Concrete with a target compressive strength of $60 \mathrm{MPa}$ and slump flow diameter of $35 \pm 2 \mathrm{~cm}$ was used.

\subsection{Materials}

The mix design was conducted in compliance with ACI $211.4 \mathrm{R}$, especially the sand and coarse aggregate. The material composition is shown in Table 1.

Table 1 Material composition

\begin{tabular}{ccccccc}
\hline Material: & OPC & Silica fume & Water & Sand & Coarse aggregate & HRWR \\
\hline $\mathrm{kg} / \mathrm{m}^{3}$ & 500 & 40 & 142.6 & 800 & 935 & 7.6 \\
\hline
\end{tabular}

The use of ordinary Portland cement (OPC) is limited to $500 \mathrm{~kg} / \mathrm{m}^{3}$ to meet the shrinkage factor closest to one (American Concrete Institute, 1992). The mechanical properties and durability of high-performance concrete can be improved with the use of nanosilica (Eddhie, 2017). The silica fume used was $8 \%$ by weight of the cement. Silica fume maximum is 15 percent; if more than 15 percent, sudden destruction can occur (Yogendran 
et al., 1987). The water to cement ratio was chosen to be between 0.26 and 0.3 because the amount of water for the hydration process is 0.26 , and the small changes in the composition of CSH gel are less than 0.3 (Termkhajornkit and Nawa, 2006). The high range water reducer (HRWR) of the composition is 1.5 percent; it is less than two percent. It was the maximum value according to the product instructions.

OPC produced by Indocement Ltd. was used. The condition of the aggregate was saturated surface dry (SSD). Fine aggregate in the form of river sand was brought from Sungai Liat (Bangka, Sumatra, Indonesia); specific gravity (SSD) was 2.605, and absorption was $0.4 \%$. The sand had been filtered and cleaned using a mixture of standard graphs obtained from the mid-gradation, according to ASTM C.33/C.33M-08. Coarse aggregate in the form of volcanic rock fragments was obtained from Banten, West Java, Indonesia. The composition of the coarse aggregate used was seventy percent the size of 13-19 mm; specific gravity (SSD) was 2.563; absorption was 1.543\%; and thirty percent the size of 6$12 \mathrm{~mm}$; specific gravity was 2.636 ; and absorption was $2.26 \%$.

To achieve desired high strength with a low water to cementitious material ratio and good workability, a polycarboxylic superplasticizer under the commercial name, Visco Crete 10, from Sika Indonesia Ltd. was added to the concrete mix as an HRWR. The HRWR dose of $1.4 \%$ cement weight was added according to the formula that is generally used in Indonesia. Local water was supplied by the Structure and Material Laboratory of Universitas Indonesia. An electrical scale was used, especially for cementitious materials and water, to obtain the accurate water to cementitious material ratio.

During the concrete mixing design stage, all of the aggregate was assumed to be under the SSD condition. A tilting drum mixture of $0.3 \mathrm{~m}^{3}$ capacity was used. The mixing started with all cementitious material in dry conditions, followed by 50 percent fine aggregate. Subsequently, fifty percent of water was added to the revolving mixture. These materials were then mixed for approximately 1.5 minutes. Next, 50 percent water was mixed homogeneously with HRWR, slowly put it into the rotating drum mixture. Thereafter, 100 percent coarse and 50 percent fine aggregate was added. With all of the materials placed into the mixer and according to their order, the concrete was mixed for approximately three minutes. The slump flow of the mixture was measured before pouring by using the Abram's cone upside down test.

\subsection{Experimental Methods}

Shrinkage was measured as strain change against time by installing SG in the specimen. The SG can detect a strain of up to $3000 \mu \varepsilon$ with an accuracy of about $0.25 \%$ and a concrete temperature of between $-80^{\circ} \mathrm{C}$ and $60^{\circ} \mathrm{C}$ with about $0.5 \%$ accuracy.

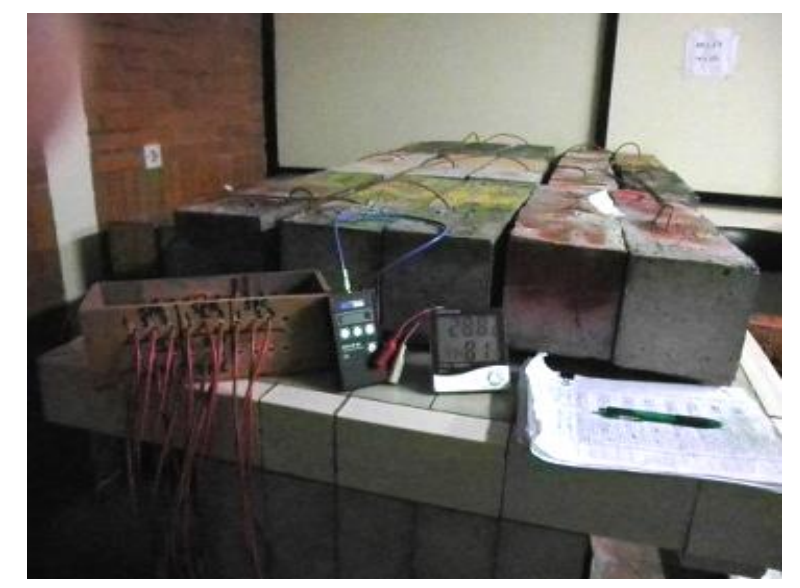

Figure 1 Specimen in a conditioned room 
Immediately after casting, specimens were covered with Styrofoam to eliminate water evaporation. The specimens were cured after demolding (one day after casting) by moisture curing until the specimens were seven days old. After this treatment, the specimens were placed in a conditioned room with a temperature of $28 \pm 3^{\circ} \mathrm{C}$ and relative humidity of $72 \pm 5 \%$ (Figure 1 ).

Complete observations were performed immediately following pouring. Due to the research time being between seven and 800 days, observations were carried out one time per day. Observation of concrete strain once a day is quite close because the growth rate of product hydration growth is slower than the age of 1 to 7 days (Kurtis, 2015).

\subsection{Shrinkage Rheological Model}

The rheological model can be created based on an understanding of particle movement behavior. Particle movement behavior determines the type of deformation. Particle movement behavior can be calculated by the change of strain. In this study, the rheological model was based on a graph of the average strain value of the three validated samples. The type of graph was determined by considering its shape; hence, the mathematical formula was made. From the mathematical formula, the type of deformation was determined. A literature study of particle flow was done to support the understanding of this formula. The rheological model was based on this mathematical formula and a literature study. The suitability between the model and the observation was considered by calculating the deviation between the observation and the model for each observation.

\subsection{Validation}

\subsubsection{Specimen data validation}

Data validation was conducted for three specimens in the timeframe of 50,100, 200, $300,400,500,600$, and 700 days and in compliance with Dixon's criteria of ASTM E178-02.

\subsubsection{Rheological model validation}

Validation of this model was done in two ways:

\subsubsection{Comparison between the observation and rheological models}

Comparison between observation and rheological model results in deviation or error. The deviation was computed by Equation 1.

$$
\text { Deviation }=\left(\varepsilon_{\text {observation }}-\varepsilon_{\text {model }}\right) .100 / \varepsilon_{\text {observation }}
$$

The relationship (R) between the two was obtained by the Excel program.

\subsubsection{Comparison with other result studies}

To test the suitability of the model on shrinkage research results, this rheological model was applied to published studies with different specimen shapes and types of concrete. The rheological model was applied to Choi and Kang's (2004) study using a high-strength SCC cylinder and Mertol et al. (2010) study using a high-strength concrete (HSC) column.

\section{Results and Discussion}

\subsection{Results}

The structural formula for the shrinkage rheological model is double Kelvin Voight in series (KV - KV) or (H I N) - (H I N), where H is the Hooke model and N is the Newton model. The first KV model is for the high hydration rate phase (Phase 1) and the second is for the low hydration rate phase (Phase 2). The shrinkage rheological model is shown in Figure 2. 


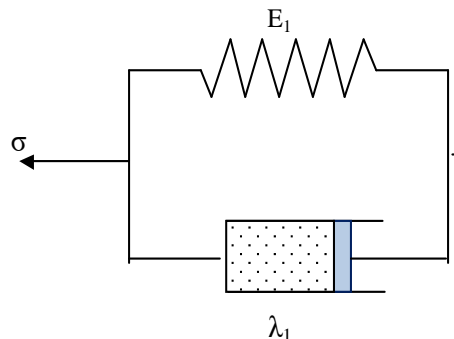

Phase 1: 7 - 16 days

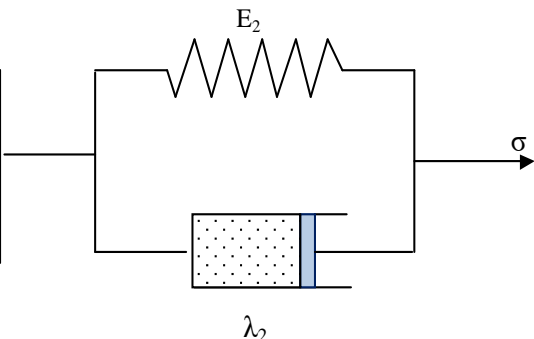

Phase 2: 17 - 800 days

Figure 2 Shrinkage rheological model

While $\sigma$ is stress, $\mathrm{E}$ is the modulus of elasticity, and $\lambda$ is the coefficient of viscosity. Parameters of the rheological model are shown in Table 2.

Table 2 Parameters of shrinkage rheological model

\begin{tabular}{cccc}
\hline Predicate & Period, days & E, Mpa & $\lambda$, day MPa \\
\hline Phase 1 (high hydration rate) & $7-16$ & $3.0755 \mathrm{E}+04$ & $20.5 \mathrm{E}+08$ \\
Phase 2 (low hydration rate) & after 16 & $3.9027 \mathrm{E}+04$ & $1.686 \mathrm{E}+08$ \\
\hline
\end{tabular}

The mathematical formulation of the rheological model is

$$
\left.\left.\varepsilon_{\text {sh }}=\left\{1-\exp \left(-k_{1} t\right)^{\alpha 1}\right)\right\} C_{1} t^{\beta 1}+\left\{1-\exp \left(-k_{2} t\right)^{\alpha 2}\right)\right\} C_{2} \cdot t^{\beta 2}
$$

where $\varepsilon_{1}$ is the shrinkage at 7-16 days, $\varepsilon_{2}$ is the shrinkage at 17-800 days, $t$ is the specimens age (days), $k, \alpha, \beta$ are the constant number depends on hydration process, treatment, curing time, curing method, the surrounding temperature, and humidity. Constant numbers are obtained by trial and error. The constant numbers can be seen in Table 3 .

Table 3 Constant numbers

\begin{tabular}{cccccc}
\hline Predicate, days & Period, days & $\mathrm{k}$ & $\alpha$ & $\mathrm{B}$ & $\mathrm{C}$ \\
\hline Phase 1 & $7-16$ & 0.000015 & 0.655 & 0.26 & 1 \\
Phase 2 & after 16 & 0.000102 & 0.24 & 0.039 & 1 \\
\hline
\end{tabular}

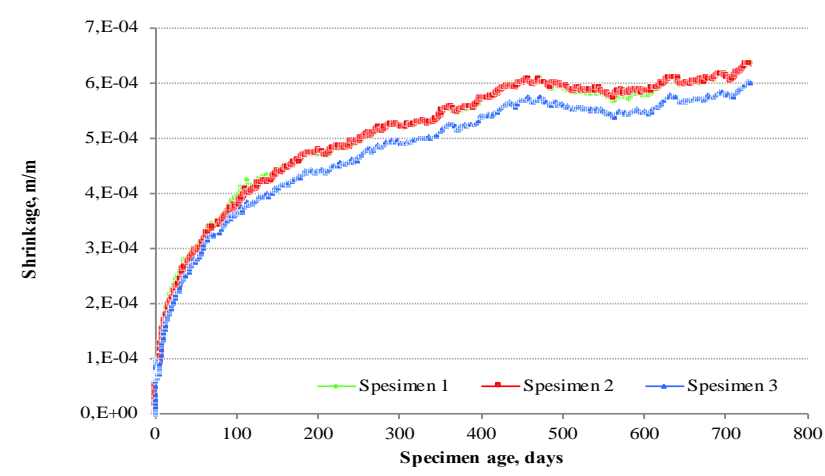

(a)

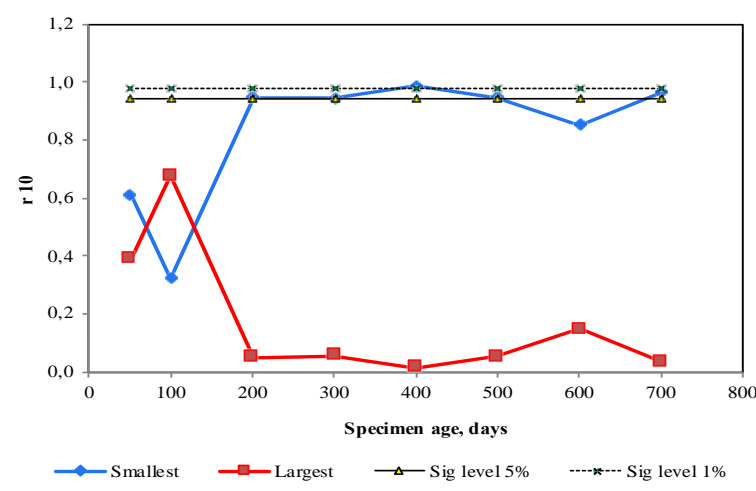

(b)

Figure 3 Experimental data from three specimens and outlying test results 


\subsection{Validation}

\subsubsection{Specimen data validation result}

The results from observing the three specimens can be seen in Figure 3a. Data validation was conducted in the timeframe of 50,100, 200,300,400,500,600, and 700 days and in compliance with Dixon's criteria of ASTM E178-02, as shown in Figure 3b. Figure 3b illustrates the smallest data values, which were outliers at 400 and 700 days and at a significance level of 5\%, but accepted at a significance level of $1 \%$; therefore, all the data were considered in the next computation.

\subsubsection{Rheological model validation result}

Rheological model validation was done by comparing deformation from the experimental and rheological models and their application for other research.

\subsubsection{Comparison between the observation and rheological models}

The comparison of shrinkage observation result and the rheological model can be seen in Figure 4a. The relation strength "R" between the models and observation is 0.9992 (Figure $4 \mathrm{a}$ ), while the deviation can be seen in Figure $4 \mathrm{~b}$. The large deviation in Phase 1 was $14.1 \%$ and $18.3 \%$, which occurred at 8.6 days and 16 days, respectively, while for Phase 2 it was $6.3 \%$ (Figure $4 \mathrm{~b}$ ).

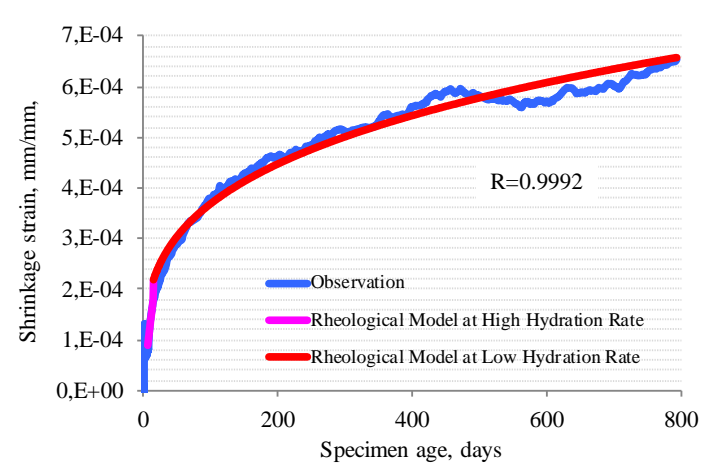

(a)

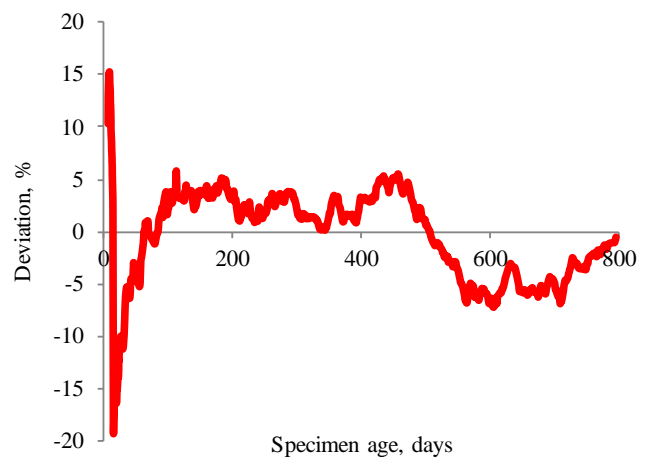

(b)

Figure 4 Observation and rheological model 7-800 days: (a) Observation and rheological model; (b) Deviation between the observation and rheological models

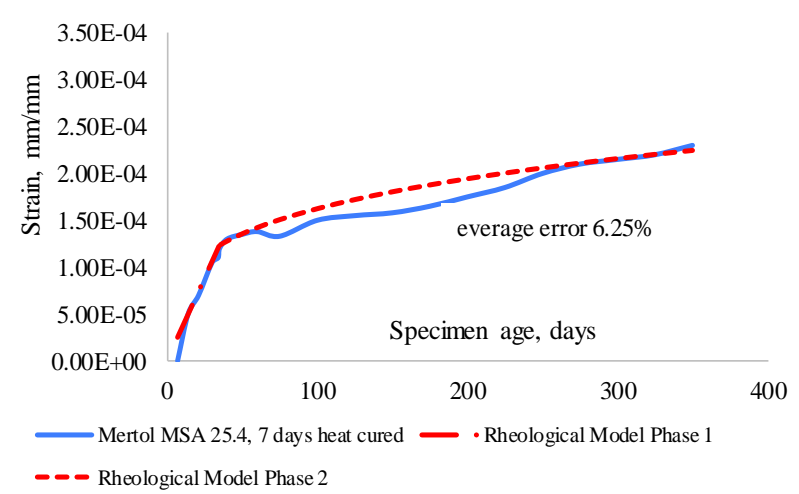

(a)

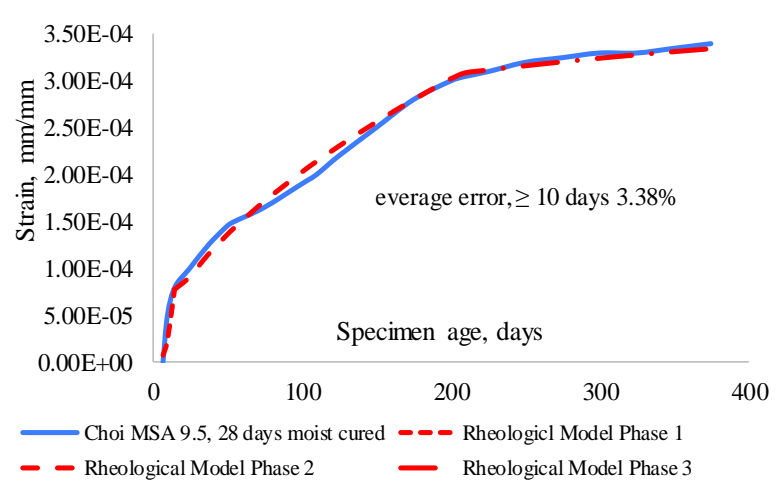

(b)

Figure 5 The application of the rheological model to the research of: (a) Mertol et al. (2010): 7 days heat-cured; (b) Choi and Kang (2004): 28 days moist-cured 
3.2.2.2. Application of shrinkage rheological model on Mertol et al. (2010) and Choi and Kang (2004)

Mertol et al. (2010) observed an HSC column shrinkage. The specimens in this study were cured using a heat-curing system for 7 days. Choi and Kang (2004) investigated shrinkage using cylindrical specimens in high-strength SCC. The specimens were treated with moisture curing for 28 days. The shrinkage rheological model was applied to both cured types with an average error of $6.25 \%$ for Mertol et al. (2010) and 3.38\% for Choi and Kang (2004). A comparison between both research and the rheological model is shown in Figures $5 \mathrm{a}$ and $5 \mathrm{~b}$. Constant numbers of the rheological models are shown in Tables 4 and 5.

Table 4 The constant numbers of Mertol et al. (2010), HSC, column, seven days heat-cured

\begin{tabular}{lccccc}
\hline Predicate, days & Period, days & $\mathrm{k}$ & $\alpha$ & $\mathrm{B}$ & $\mathrm{C}$ \\
\hline Phase 1 & $7-30$ & $3.5 \mathrm{E}-06$ & $1.1 \mathrm{E}-01$ & $9.00 \mathrm{E}-01$ & 1 \\
Phase 2 & after 30 & $5.0 \mathrm{E}-05$ & $1.0 \mathrm{E}-01$ & $1.57 \mathrm{E}-01$ & 1 \\
\hline
\end{tabular}

Table 5 The constant numbers of Choi and Kang (2004), SSC, cylinder, 28 days moist-cured

\begin{tabular}{cccccc}
\hline Predicate, days & Period, days & $\mathrm{k}$ & $\alpha$ & $\mathrm{B}$ & $\mathrm{C}$ \\
\hline Phase 1 & $7-15$ & $2 \mathrm{E}-08$ & 3.5 & 0 & 1 \\
Phase 2 & $15-200$ & $1.4 \mathrm{E}-05$ & 0.79 & $-2.1 \mathrm{E}-01$ & 1 \\
Phase 3 & After 200 & $1.5 \mathrm{E}-04$ & 0.17 & $-3.5 \mathrm{E}-02$ & 1 \\
\hline
\end{tabular}

\subsection{Discussion}

According to the observation (Figure 1), there are two phases in the model (Figure 2 and Table 1). Phase 1 had the highest rate of product hydration growth and the highest rate of decreasing pore numbers. Phase 2 had a low hydration rate and a low decreasing pore number. In this study, these changes became the points where changes from high hydration rates to low hydration rates occur. The periods of Phase 1 are dependent on the type of mixture (Tables 1, 2, 3, and 4), type of curing, water diffusion, and type of structural element. Water diffusion in concrete with the aggregate being used as an internal curing agent was delayed, leading to a decrease in shrinkage (Yadav et al., 2018). Therefore, the shrinkage strain $\left(\varepsilon_{\text {sh }}\right)$ can be expressed in Equation 3.

$$
\varepsilon_{\mathrm{sh}}=\varepsilon_{\mathrm{sh} 1}+\varepsilon_{\mathrm{sh} 2}
$$

The deformation is caused by inner stress, which leads to particle flow. Van Vlack (1973) expressed particle flow $(\varepsilon)$ as the following equation:

$$
\varepsilon=\varepsilon_{0}(1-\exp (-\mathrm{tE} / \lambda))
$$

where $\varepsilon_{0}$ is initial strain, $\lambda$ is normal viscosity, $\mathrm{E}$ is modulus of elasticity, and $\mathrm{t}$ is time. If $\mathrm{k}=\mathrm{k}=\mathrm{E} / \lambda$, Equation $4 \mathrm{a}$ can be written as Equation $4 \mathrm{~b}$ as follows:

$$
\varepsilon=\varepsilon_{0}(1-\exp (-\mathrm{kt}))
$$

If $\boldsymbol{\varepsilon}_{0}$ is assumed to be a multiplier factor, (1-exp(-kt)) represents the basic model of particles.

$$
\text { Basic model of particle flow: } \varepsilon_{\text {Van Vlack }}=(1-\exp (-\mathrm{kt}))
$$

\subsubsection{Multiplier factor}

Hydration reaction leads to the occurrence of initial stress. The growth of hydration products creates stress called 'crystal growth stress. In the product, hydration occurs and 
pores can be contained in it. This process and the resulting pores trigger capillary tension, disjoining pressure, and surface tension. Bažant et al. (1997) mentioned the stress of crystal growth, capillary tension, disjoining pressure, and surface stress as microprestress. The stress continues until the hydration reaction ends. Hence, the initial strain is a timedependent function. Hydration stress is a major factor that affects initial strain during the high hydration rate phase (Phase 1). In general, such a phase happens during a range of 7 28 days. In this study, the range of Phase 1 was 7-16 days (Table 1). A high rate of decreasing pore number occurred simultaneously with the high rate of product hydration growth. Penetration of surrounding temperature was also influenced by pore conditions. The decreasing pore number correlated with product hydration growth, which was a function of time. The model of the mechanism is assumed as a time function with a constant exponential (Equation 5).

In the next phase, the hydration process occurred at a low rate. The size and number of pores also changed at a low rate. The penetration of Surrounding Relative Humidity (SRH) correlated with the pore's amount and size in the concrete. Inner water evaporation correlated with the amount and size of the pores and SRH. Thus, the multiplier factor can be described as Equation 5.

$$
\varepsilon_{0 n}=C_{n} t^{\beta n}
$$

where $\mathrm{n}$ is phase number, $\mathrm{C}$ is constant, $\mathrm{t}$ is time, $\beta$ is a reflection of product hydration maturity, pores, and SRH.

\subsubsection{Particle flow model}

The particle flow model by Van Vlack (1973), in accordance with Equations 4a and 4b, is displayed in Figure 6a. The number of moving particles, which has been stated in Equation $4 \mathrm{c}$, has a direct correlation with strain or $\varepsilon$ (Figure $6 \mathrm{a}$ ). If the driving energy decreases, some particles stop moving. The still particles, according to Van Vlack (1973), are exp $(-\mathrm{tE} / \lambda)$, as displayed in Figure 6a. If $\mathrm{k}$ is used, the still particles would equal $\exp (-$ $\mathrm{kt})$. "Kt" is assumed as a unity that influences the flow type.

Shrinkage is the decreasing volume without applied load. The particles start to move by the heat of hydration, which results in free energy. Another driving energy that moves particles is microprestress. Such energy makes particles under shear stress. The shear stress will decrease according to hydration product maturity. Hydration product maturity, the change in free water, microprestress, surrounding temperature, and SRH penetration causes concrete viscosity $(\lambda)$ to change.

The decrease in pore number is in accordance with the growth of hydration products (Kurtis, 2015). Changes in pore dimensions and pore numbers cause the evaporation ability of pore water to decrease. A lower level of humidity is needed to evaporate water in small pores than in large pores (Thomas and Jenning, 2008). The decrease in pore dimensions also causes some particles to stop moving. The decreasing ability to evaporate is a function of time; thus, particles still have a function of time.

Along with the hydration process, the surrounding temperature and SRH penetrate the concrete through the open pores, then into the pores network. Such penetration will influence disjoining pressure and increase the flow rate of particles. This flow is continuous but not smooth because the flow meets some barriers. Product hydration becomes a barrier for the particles to flow smoothly.

The barrier makes some particles move slowly or even stop. Therefore, still particles are affected by the decreasing stress due to decreasing product hydration growth (function of time) and increasing barrier (function of product hydration growth). This means still particles have a tiered time function. The form of curve or particle flow model of shrinkage must reflect this flow mechanism. 
Based on the description above, still particles are not only in the form of exp(-kt) but also in the power form. The power form results in a different slope of strain (Figure 6b). The power type of still particles is assumed as " $(\mathrm{kt})^{\alpha}$." Thus, the basic particle flow model can be approached as Equation 6.

$$
\text { Basic particles flow model }=\left(1-\exp \left(-\mathrm{k}_{1} \mathrm{t}\right)^{\alpha}\right)
$$

where $\alpha$ is the reflection of the hydration product number, decreasing stress, and SRH penetration.

By entering the multiplier factor into the basic particle flow, shrinkage strain is obtained, as shown in Equation 7.

$$
\left.\varepsilon_{\text {sh }}=\left\{1-\exp (-\mathrm{kt})^{\alpha}\right)\right\} C \mathrm{t}^{\beta}
$$

The first phase is dominated by a hydration process or high hydration rate; the following phase describes the domination of SRH penetration. For the two phases, shrinkage strain is shown in Equation 2.

\subsubsection{Shrinkage rheological model}

The basic rheological model is the solid elastic described by Hooke as a spring, the plastic described by St Venant as a sliding box, and the thick liquid described by Newton as a dash-pot. Viscosity is one of the physical properties of a material. Viscosity is influenced by energy, changes in volume, and temperature, triggered by shear forces between moving particles. The solid material will flow like a liquid, even though it is sluggish and under small stress (Sobotka, 1984). The best model of the material is viscoelastic. Viscoelastic expresses elasticity as a reaction to deformation and viscosity, which states the response to the rate of deformation. Viscosity strain is the strain on the solidified element. Viscosity value is a function of microprestress $(\sigma)$, as shown in Equation 8.

$$
\lambda=\frac{\sigma}{\mathrm{d} \varepsilon / \mathrm{dt}}
$$

Because the microprestress in Phase 2 is smaller than in Phase 1, the viscosity $(\lambda)$ in Phase 2 is smaller than in Phase 1 (Table 1).

The modulus of elasticity is influenced by the volume that has solidified and can sustain the load. The elasticity modulus of Phase 2 is greater than that of Phase 1 (Table 1); thus, the solidified volume of Phase 2 is greater than that of Phase 1.

The viscoelastic solid of Kelvin Voight was described as a parallel arrangement of Hooke (H) and Newton (N), which is shown in Figure 2 only Phase 1 or Phase 2.

$$
\begin{gathered}
\sigma=\sigma_{H}+\sigma_{N}=\mathrm{E} \varepsilon+\lambda \frac{\mathrm{d} \varepsilon}{\mathrm{dt}} \\
\varepsilon=\frac{\sigma}{\mathrm{E}}\left(1-\mathrm{e}^{\frac{\mathrm{Et}}{\lambda}}\right)
\end{gathered}
$$

In the shrinkage case, the pure viscoelastic model becomes invalid. However, the application of this model to concrete must consider the fact that concrete is not only nonlinear strain but has a unique strain rate, as mentioned above. The characteristics are shown in Equations 5 and 6.

Equation $9 \mathrm{~b}$ is similar to Equation $4 \mathrm{a}$ with additional parameters based on the shrinkage mechanism. Based on this similarity, the rheological model of shrinkage is single or multi Kelvin-Voigt in the series order, as shown in Figure 2, with the mathematical model shown in Equation 2.

\subsubsection{Aplication of the model}

The application of this rheological model to column structure elements of HSC, which was observed by Mertol et al. (2010) with 7-day heat curing, shows good results with an 
average error of $6.25 \%$ (Figure 5a). Good results (average error for more than 10 days is $3.38 \%$ ) were also obtained from the application of this rheological model of Choi and Kang (2004) using a high-strength SCC cylinder with 28-day moist curing (Figure 5b). The rheological model for Mertol et al. (2010) is double Kelvin-Voigt in series and for Choi and Kang (2004) is triple Kelvin-Voigt in series.

The difference in values of $k, \alpha$, and $\beta$ occurs because of differences in the mixture, treatment immediately after casting, curing method, element structure, casting time, SRH, and surrounding temperature.

\section{Highlight}

The results of this study reveal that the shrinkage of concrete can be expressed by the rheological model, whereas, previously, the concrete rheology model was only for creep. Observation of concrete shrinkage was carried out for 7-800 days. This is so that the observations included shrinkage from the high rate of hydration to completion, the combination of hydration and environmental influences, and environmental influences.

This rheological model is suitable for various types of concrete in various forms with heat or moisture curing.

\section{Conclusions}

The main conclusion of the study is that the rheological model of shrinkage is a single or series arrangement of the Kelvin-Voight model with: (1) Parameters reflecting the time that influenced the product hydration rate, hydration product number, and its maturity as a barrier to the viscoelastic flow; (2) Parameters that reflect the initial strain in each phase as multipliers.

This rheological model can be applied to beam, column and cylinder, heat- and moistcured, HSC concrete and high-strength self-consolidation concrete, and varied maximum size aggregate.

\section{Acknowledgements}

The support from the University of Lampung and the Structure and Material Laboratory of the Faculty of Engineering, University of Indonesia is gratefully acknowledged.

\section{References}

American Concrete Institute, 1992. ACI 209R-92: Prediction of Creep, Shrinkage, and Temperature Effects in Concrete Structure, pp. 1-47

American Concrete Institute, 1993. ACI 211.4R: Guide for Selecting Proportion for High Strength Concrete with Portland Cement and Fly Ash, pp. 272-283

American Society for Testing and Materials International, C33/C.33M-08, 2009, Construction, Concrete, and Aggregates: Standard Specification for Concrete Aggregates, West Conshohocken, pp. 12-1

American Society for Testing and Materials International, C 78-08, 2009, Construction, Concrete, and Aggregates: Test Method for Flexural Strength of Concrete, West Conshohocken

American Society for Testing and Materials International, E 178-02, 2002, Standard Practice for Dealing with Outlying Observation, pp. 1-18 
Bažant, Z.P., Fellow, ASCE, Hauggaard, A.B., Baweja S., Ulm, F.J., 1997. MicroprestressSolidification Theory for Concrete Creep. I: Aging and Drying Effects. Journal of Engineering Mechanics, Volume 123(11), pp. 1188-1194

Bentz, D.P., 2018. Concrete Rheology. In: Inorganic Materials Group, Engineering Laboratory, Materials and Structural System Division, NIZT

Choi, Y., Kang, M-M., 2004. SCC: Long-term Performance of High Strength Concrete. The Indian Concrete Journal, Volume 78(6), pp. 425-431

Eddhie, J., 2017. Strength Development of High-Performance Concrete using Nanosilica. International Journal of Technology, Volume 8(4), pp. 728-736

Elzokra, A.A.E., Al Houri, A., Habib, A., Habib, M., Malkawi, A.B., 2020. Shrinkage Behavior of Conventional and Nonconventional Concrete: A Review. Civil Engineering Journal, Volume 6(9), pp. 1839-1981

Ferraris, C.F., Billberg, P., Ferron, R., Feys, D., Hu, J., Kawashima, S., Koehler, E., Sonebi, M., Tanesi, J., Tregger, N., 2017. Role of Rheology in Achieving Successful Concrete Performance. ACI Journal, Volume 39(6), pp. 43-51

Ferraris, C.F., 1999. Measurement of the Rheological Properties of High-Performance Concrete: State-of-the-Art Report. J. Research-National Inst. Stand. Technol., Volume 104, pp. 461-478

Hackley, V.A., Ferraris, C.S., 2001. Guide to Rheological Nomenclature: Measurements in Ceramic Particulate Systems, NIST, Special Publication 946, pp. 1-31

Hedegaard, B., 2020. Creep and Shrinkage Modelling of Concrete using Solidification Theory. Journal of Materials in Civil Engineering, Volume 32(7), p. 04020179

Kurtis, K., 2015. Portland Cement Hydration. Course Hero. Georgia Institute of Technology, CEE 8813b. pp. 1-35

Mau, S., Yanuar, Pamitran, A.S., 2020. Rheology Characteristics and Critical Velocity of Particle-laden Flow Affected by Three-lobed Spiral Pipe. International Journal of Technology, Volume 11(2), pp. 248-258

Mertol, H.C., Rizkalla, S., Zia, P., Mirmiran, A., 2010. Creep and Shrinkage Behaviour of High Strength Concrete and Minimum Reinforcement Ratio for Bridge Column. PCI Journal, Summer, pp. 138-153

Sobotka. Z., 1984. Rheology of Materials and Engineering Structures. Elsevier, Czechoslovak

Sobotka, Z. 1962. Some Problems of Non-linear Rheology Second-order Effects in Elasticity, in Second-order Effects in Elasticity, Plasticity and Fluid Dynamics. In: International Symposium, Haifa, Israel, April 23-27, Edited Markus Reiner and David Abir, pp. 362390

Termkhajornkit, P., Nawa, T., 2006. A Study of Composition of C-S-H Gel in Cement Paste. Recent Development of Concrete Technology and Structure. In: $2^{\text {nd }}$ ACF International Conference, November

Thomas, J., Jenning, H., 2008. Materials of Cement Science Primer. Final report, Infrastructure Technology Institute. Northwestern University, Evanston, 96 pages

Van Vlack, L.H., 1973. Materials Science for Engineers. Addison Wesley, 4, USA

Yadav, N., Deo, S.V., Ramtekkar., 2018. Workable and Robust Concrete using High Volume Construction and Demolition Waste in Sub-tropical Climate. International Journal of Technology, Volume 9(3), pp. 537-548

Yogendran, V., Langan, B.W., Haque, M.N., Ward, M.A. 1987. Silica-fume in High Strength Concrete. ACI Material Journal. Volume 84(2), pp. 124-129 